\title{
A Preliminary Study On the Electrical Signatures of Some Iron and Stony Meteorites and Their Dependence On Nickel Content
}

\author{
Bassem S. NABAWY ${ }^{1}$ and Pierre ROCHETTE ${ }^{2}$ \\ ${ }^{1}$ Department of Geophysical Sciences, National Research Center, Cairo, Egypt \\ e-mail: bsnabawy@yahoo.co.uk (corresponding author) \\ ${ }^{2}$ Aix-Marseille Université, CNRS, IRD, CEREGE UM34, Aix en Provence, France
}

\begin{abstract}
The present study is considered as an exploratory study of electrical properties of meteorites at variable current frequencies, called the electrical signature. The electric resistivity has been measured at different frequencies, varying between 1 and $100 \mathrm{KHz}$ for some iron meteorites (Mundrabilla and Gibeon meteorites), stony meteorite samples (NWA 869, NWA 7629 and Ghubara) and Fe-Ni alloys, of known Ni concentration, which have been prepared and used as standards to be compared with the studied meteorites. In addition, SEM studies supported by EDX technique have been applied. The SEM and EDX displays enabled us to obtain the chemical composition and internal structural fabrics of the studied samples. Porosity and density (bulk and grain densities) have also been measured for both types of meteorites. Porosity values of the studied meteorites are very low $(\varnothing \leq 3 \%$ ) and correspond to micro vugs and cracks. The grain density of non-weathered samples varies from $3.48 \mathrm{~g} / \mathrm{cm}^{3}$ for the stony meteorites to $7.91 \mathrm{~g} / \mathrm{cm}^{3}$ for the iron meteorites. The obtained electrical signatures are diagnostic for each type and can be used to detect quantitatively the concentration of Ni. The electrical signature of stony meteorites is much simpler than that of iron meteorites, and simpler signatures have been obtained at higher Ni concentrations.
\end{abstract}

Key words: electrical signature, porosity, iron meteorites. 


\section{INTRODUCTION}

Meteorites are samples coming from the outer space to the Earth providing information on the solar system. Unreachable information relevant to the genesis, evolution and composition of the Earth can also be obtained from the study of meteorites. Iron-bearing minerals are an important component of meteorites that carry a lot of information about their celestial history (Dodd 1981, Rubin 1997, Bland et al. 2002, Verma and Tripathi 2004). Meteorite composed mainly of iron-nickel alloys are called iron meteorites and comprise about $5 \%$ of the total witnessed meteorites. Since they are denser than the stony meteorites, the iron meteorites account for almost $90 \%$ of the mass of all known meteorites (Darling 2003). All the largest known meteorites are of this type.

A number of analytical techniques devoted to mineralogy, petrology, elemental and isotopic geochemistry are used to characterize and classify the different meteorites.

The physical properties of meteorites are important features for understanding the origin and weathering of the different meteorites. The basic physical measurements of rock samples include bulk and grain density, porosity, permeability, and electrical resistivity as well as magnetic properties, in particular magnetic susceptibility, and their study in meteorite is relevant for understanding physical processes in solar system bodies (e.g., Cuzzi et al. 2008, Teiser and Wurm 2009, Davison et al. 2014).

Porosity and grain density are the most important physical properties of meteorites. They provide insight into accretion, evolution, impact history, mineralogy, internal strength, and structure of solar system bodies. The grain density and porosity of meteorites are fundamental "ground truth" for understanding their composition and structure (Britt and Consolmagno 2003).

Meteorites are always denser than the asteroids and have rare pore spaces of negligible volume. Asteroids commonly appear to have low densities (Yeomans et al. 1999) that imply much higher porosity than the typical meteorites (Consolmagno et al. 1998, Flynn et al. 1999, Wilkison and Robinson 2000). Porosity has been measured directly for numerous Apollo regolith breccias (McKay et al. 1986, 1989; Corrigan et al. 1997, Warren 2001) using point-counting technique and constrained indirectly through bulk density measurements for more Apollo samples (Talwani et al. 1973). Most asteroids, for which porosities have been inferred, have porosities ranging from $20 \%$ to $>50 \%$, with a mean around 30\% (Britt et al. 2002, Flynn 2014).

According to Wasson (1974) and Hamano and Yomogida (1982), the porosity of achondrites and C-, L-, and H-chondrites varies from less than 1\% up to $25 \%$. 
Corrigan et al. (1997) and Consolmagno et al. (1998) have investigated the porosity of a large number of chondritic interplanetary dust particles and meteorites by three techniques: standard liquid/gas flow techniques, noninvasive ultrasonic technique, and image processing of back scattered electron microscopy. They also measured the gas and liquid permeabilities of some chondrites by two techniques: standard liquid/gas flow techniques, and a new, non-destructive pressure release technique. They found that chondritic interplanetary dust particles (IDPs) have somewhat bimodal porosity distribution. Peaks are present at 0 and $4 \%$ porosity with a tail extends to $50 \%$ (Bland et al. 2011). Permeabilities of the investigated chondrites vary by several orders of magnitude from 0.0001 up to 6.72 millidarcy.

Helium pycnometry is considered as the most precise method, due to its ability to invade pores down to $10 \eta \mathrm{m}$. Recently, several studies have been applied for measuring porosity and grain densities of meteorites and asteroids using helium injection technique (Kohout et al. 2014a, b). Therefore, measuring porosity and grain density using the helium injection technique was applied for the present study.

The electrical resistivity is among the most important physical properties, but in spite of the great importance of meteorites, their electrical properties have been rarely explored. This may be due to the great variation of the mineralogical composition of meteorites, ranging from mostly metalic composition (iron meteorites) to silicates (stony meteorites).

The electrical resistivity is controlled by the physical properties of the assemblage; e.g., crystal size, structures, and mineralogical composition, as well as frequency and temperature. The meteorites, as solid materials, have mostly low porosity and therefore exert a great resistance for charge transport.

Increasing the electric frequency of the applied current increases the energy of the electrons flowing through the studied material and therefore increases the conductivity of the studied material, i.e., it is expected that the electrical resistivity decreases with increasing electric frequency. Nevertheless, a peak of energy of saturation is expected at low frequencies, causing abrupt increase in resistivity; it is something like a signature or like an electric threshold to be overcome.

Therefore, measuring the electrical resistivity at variable frequencies can be used to characterize the studied material. The electrical behavior "electrical signature" may provide a fast and nondestructive technique to quantify the composition of meteorites in terms of their electrical properties. 


\section{SAMPLES DESCRIPTION}

In the present study, the petrophysical properties of five meteorites, different in nickel concentration, have been characterized: two iron meteorites (Gibeon and Mundrabilla, mostly composed of metallic iron-nickel, with minor sulfides and phosphorous) and three stony meteorites of ordinary chondrite type (NWA 869, NWA 7629, and Ghubara), consisting of a mixture of silicates, metal and sulfides, with dominant silicates. The choice of samples, from the CEREGE collection, was guided by the need to have a cut slab of sufficient surface and thickness for the electric measurement. Overall descriptions of the composition of the present meteorites are introduced in the following section.

\subsection{Stony meteorite samples}

NWA869 is an ordinary chondrite collected in Sahara by M. Franco. It is genomict breccia consisting of angular clasts in a finer grained matrix. Most clasts are of type 6 with less than 1\% volume of type 3 (Metzler et al. 2008). Classification is L3-6 regolith breccia, with low weathering grade W1.

NWA 7629 is an ordinary chondrite collected from the Great Sahara in NW Africa. It is stony with some silver iron spots with weathering grade (W1). Its magnetic properties have been studied and classified as L5 Chondrite by Tikoo et al. (2013).

Ghubara (L5 Chondrite) is a blackened regolith breccia, found in Oman in 1954. The larger silvery spots on the sliced side are metals. The smaller, whitish parts are xenoliths. These are actually fragments of another chondritic body, which has been incorporated into Ghubara $(21.33 \%$ iron, $4.4 \%$ of the total volume), probably from an impact in space (Krzesińska 2011). It contains several kinds of clasts, different in textures. They range from un-equilibrated chondritic material to highly recrystallized, impactmelted, and achondrite-like inclusions (Vinogradov and Vdovykin 1963, Binns 1967, Krzesińska 2011).

\subsection{Iron meteorite samples}

Gibeon is a fine octahedrite iron meteorite, ranked as a member of IVA group. It fell in the prehistoric time and was discovered in Namibia in 1836. The Gibeon Meteorite has been named after Gibeon Town in southern Namibia. It is an iron-nickel alloy (Fe $91.8 \%$ and $\mathrm{Ni} 7.7 \%$ as well as traces of Co 0.5\%, Table 1) (Meteoritical Bulletin 1970, Buchwald 1975, Wasson and Richardson 2001, Weisberg et al. 2006).

Mundrabilla (medium octahedrite) is a medium octahedrite iron meteorite ranked as a member of IAB complex group (Wasson and Kallemeyn 2002). It was found in Western Australia (at Nullarbor Plain) in 1911. It is 
Table 1

Chemical composition in percentage of the studied iron meteorites and the standard alloys using EDX technique

\begin{tabular}{|c|c|c|c|c|c|c|c|c|c|c|c|c|c|c|c|}
\hline & $\mathrm{O}_{2}$ & $\mathrm{Mg}$ & $\mathrm{Al}$ & $\mathrm{Si}$ & $\mathrm{Cl}$ & $\mathrm{Ca}$ & $\mathrm{Fe}$ & $\mathrm{Ni}$ & $\mathrm{Mn}$ & $\mathrm{Cr}$ & $\mathrm{Co}$ & $\mathrm{C}$ & $\mathrm{P}$ & $\mathrm{S}$ & Ref. \\
\hline Gibeon & - & - & - & - & - & - & 91.80 & 7.70 & - & - & 0.500 & - & 0.040 & - & $\begin{array}{c}\text { Met. Bull. } \\
(1970)\end{array}$ \\
\hline $\begin{array}{c}\text { Mundrabilla } \\
\text { (metal ph.) }\end{array}$ & - & - & - & - & - & - & 91.15 & 7.88 & n.d. & trace & 0.520 & 0.26 & 0.345 & 0.006 & $\begin{array}{c}\text { Weinke } \\
(1977)\end{array}$ \\
\hline $\begin{array}{c}\text { Mundrabilla } \\
\text { (sulfide ph.) }\end{array}$ & - & - & - & - & - & - & 60.48 & 0.06 & 0.40 & 1.42 & 0.003 & 1.24 & - & 36.200 & $\begin{array}{c}\text { Weinke } \\
(1977)\end{array}$ \\
\hline Mundrabilla & - & - & - & - & - & - & 68.95 & 31.05 & - & - & - & - & - & - & Present st. \\
\hline Alloy-9.7 & - & - & - & - & - & - & 89.82 & 10.18 & - & - & - & - & - & - & Present st. \\
\hline Alloy-17.5 & - & - & - & - & - & - & 82.76 & 17.24 & - & - & - & - & - & - & Present st. \\
\hline Alloy-30.0 & - & - & - & - & - & - & 69.90 & 30.10 & - & - & - & - & - & - & Present st. \\
\hline NWA 7629 & 17.08 & 9.14 & - & 45.49 & 7.65 & - & 10.55 & - & - & 10.09 & - & - & - & - & Present st. \\
\hline $\begin{array}{c}\text { NWA 869 } \\
\text { (stony ph.) }\end{array}$ & 19.85 & 12.23 & 0.58 & 36.09 & 5.56 & 6.43 & 9.23 & - & - & - & - & 4.46 & - & - & Present st. \\
\hline $\begin{array}{c}\text { NWA 869 } \\
\text { (sulfide ph.) }\end{array}$ & - & - & - & - & - & - & 20.96 & - & - & - & - & 5.13 & - & 73.920 & Present st. \\
\hline
\end{tabular}

the largest meteorite ever found (24 ton, Grady 2000; and Meteoritical Bulletin 2013). Mundrabilla's structure is very exceptional, consisting of about $65-75 \%$ iron-nickel with sulfide inclusions, mainly troilite (FeS), present in small nodules accounting for 25 to $35 \%$ of the volume of the meteorite (DeLaeter 1972, Müller 1977).

\subsection{Platelet alloys}

In addition to the studied meteorites, three $\mathrm{Fe}-\mathrm{Ni}$ metallic discs of known composition $(9.67,17.51$, and $30.04 \% \mathrm{Ni})$ were prepared as reference materials. The preparation and fusion were done under vacuum in a crucible, with cooling rate of $100^{\circ} \mathrm{C}$ per minute.

\section{MEASURING TECHNIQUES}

The studied meteorites and the reference $\mathrm{Fe}-\mathrm{Ni}$ platelets were gently polished to have two very smooth parallel faces, cleaned and dried, to be ready for electrical measurements (at $60^{\circ} \mathrm{C}$ for 48 hours). Thicknesses of the studied samples and discs were measured using a digital micrometer.

Electric measurements with two electrodes, using a computerized Hioki 3522-50LCR Hitester impedance analyzer up to $100 \mathrm{kHz}$, were conducted at ambient conditions to match the electrical behavior of the studied meteorites. The measurements were done at stepwise 54 selected electric frequencies 
Table 2

Average bulk density, grain density, and porosity of the studied meteorites as well as the Ni content of the studied alloys and the Mundrabilla meteorite

\begin{tabular}{|l|c|c|c|c|c|c|}
\hline \multicolumn{1}{|c|}{ S. No. } & $\begin{array}{c}\text { Grain } \\
\text { density } \\
{\left[\mathrm{g} / \mathrm{cm}^{3}\right]}\end{array}$ & St. dv. & $\begin{array}{c}\text { Bulk } \\
\text { density } \\
{\left[\mathrm{g} / \mathrm{cm}^{3}\right]}\end{array}$ & St. dv. & $\begin{array}{c}\text { Porosity } \\
{[\%]}\end{array}$ & $\begin{array}{c}\mathrm{Ni} \\
{[\%]}\end{array}$ \\
\hline NWA 869 & 3.4989 & 0.0077 & 3.4211 & 0.0392 & 2.22 & - \\
NWA 7629 & 3.4832 & 0.0114 & 3.3830 & 0.0114 & 2.88 & - \\
Gibeon & 7.4401 & 0.0104 & 7.1991 & 0.0061 & 3.23 & 7.70 \\
Mundrabilla & 7.7840 & 0.0004 & 7.5608 & 0.0006 & 2.87 & 7.88 \\
Alloy-9.7 & 7.9053 & 0.0006 & 7.5747 & 0.0006 & 4.18 & 9.67 \\
Alloy-17.5 & 7.9797 & 0.0003 & 7.4180 & 0.0008 & 7.04 & 17.51 \\
Alloy-30 & 8.1954 & 0.0006 & 7.6496 & 0.0005 & 6.66 & 30.04 \\
\hline
\end{tabular}

$(1 \mathrm{~Hz}, 2,3, . ., 10,20,30, \ldots, 100,200,300 \mathrm{~Hz}, \ldots 1 \mathrm{kHz}, 2, \ldots, 10,20 \ldots$ and $100 \mathrm{kHz}$ ) using $\mathrm{AC}$ current within a range of $1 \mathrm{~Hz}$ up to $100 \mathrm{kHz}$.

The electrical resistivities have been measured six times against frequencies for each sample and the average values and behavior were considered.

The dry weight of the studied samples was measured using an electronic balance ( $0.1 \mathrm{mg}$ precision), and the grain volume was measured using the UltraPyc 1200 e at $15 \mathrm{psi}$ and ambient temperature. The grain volume was measured by injecting the helium directly into the cell without isolating the sample, whereas the bulk volume was determined via Archimedean method for the bulk density measurements (Table 2). The grain volume measurements have been repeated 5 times for each sample and the average values have been considered. The bulk and grain densities were then calculated precisely, as a ratio between the weight and the volume.

Scanning electron microscopy, equipped with EDX chemical analysis, was applied to the present meteorites and alloys to image and reveal their internal structure and their chemical compositions. Imaging and elemental analyses were done using JEOL JXA-810A Electron Probe Microanalyzer at the central laboratory of the National Research Centre in Cairo. Three to five SEM images have been taken for each sample as well as three EDX spots analyses.

\section{RESULTS}

\subsection{Electrical behavior "signatures"}

The studied meteorites have been subjected to AC current at variable frequency ranging from $1 \mathrm{~Hz}$ to $100 \mathrm{kHz}$ (Table 3). The electrical signature of the prepared alloys and meteorites can be evidenced by plotting the measured electrical resistivity versus the different applied electric frequency on X-Y plot (Figs. 1-3). 
Table 3

Electrical values for the studied meteorites and alloys

\begin{tabular}{|c|c|c|c|c|c|c|c|}
\hline \multirow{2}{*}{\multicolumn{2}{|c|}{$\begin{array}{l}\text { Meteorite } \\
\text { type }\end{array}$}} & \multicolumn{3}{|c|}{ Pre-saturation stage } & \multicolumn{3}{|c|}{ Saturation stage } \\
\hline & & Peak-1 & Peak-2 & Peak-3 & Steep stage & $\begin{array}{c}\text { Transitional } \\
\text { stage }\end{array}$ & Steady stage \\
\hline \multirow{3}{*}{ 空 } & $\begin{array}{c}\text { NWA } \\
869\end{array}$ & $\begin{array}{l}60 \mathrm{~Hz} \\
121149 \Omega . m\end{array}$ & - & - & $\begin{array}{l}60-1 \mathrm{kHz} \\
121149- \\
33823 \Omega . m\end{array}$ & $\begin{array}{l}1-20 \mathrm{kHz} \\
33823- \\
4674 \Omega . \mathrm{m}\end{array}$ & $\begin{array}{l}20-100 \mathrm{kHz} \\
4674- \\
1050 \Omega . \mathrm{m}\end{array}$ \\
\hline & $\begin{array}{c}\text { NWA } \\
7629\end{array}$ & $\begin{array}{l}60 \mathrm{~Hz} \\
161119 \Omega . \mathrm{m}\end{array}$ & - & - & $\begin{array}{l}60-1 \mathrm{kHz} \\
161119- \\
28365 \Omega . \mathrm{m}\end{array}$ & $\begin{array}{l}1-20 \mathrm{kHz} \\
28365- \\
3334 \Omega . \mathrm{m}\end{array}$ & $\begin{array}{l}20-100 \mathrm{kHz} \\
3334- \\
1690 \Omega . \mathrm{m}\end{array}$ \\
\hline & $\begin{array}{l}\text { Ghu- } \\
\text { bara }\end{array}$ & $\begin{array}{l}100 \mathrm{~Hz} \\
454438 \Omega . \mathrm{m}\end{array}$ & $\begin{array}{l}10 \mathrm{kHz} \\
320425 \Omega . \mathrm{m}\end{array}$ & $\begin{array}{l}20 \mathrm{kHz} \\
407471 \Omega . \mathrm{m}\end{array}$ & & $\begin{array}{l}20-40 \mathrm{kHz} \\
407471- \\
21627 \Omega . \mathrm{m}\end{array}$ & $\begin{array}{l}40-100 \mathrm{kHz} \\
21627- \\
13113 \Omega . \mathrm{m}\end{array}$ \\
\hline \multirow{2}{*}{ ఏ్తి } & $\begin{array}{l}\text { Gibe- } \\
\text { on }\end{array}$ & $\begin{array}{l}90 \mathrm{~Hz} \\
108871 \Omega . m\end{array}$ & $\begin{array}{l}1 \mathrm{kHz} \\
111800 \Omega . \mathrm{m}\end{array}$ & $\begin{array}{l}10 \mathrm{kHz} \\
209209 \Omega . \mathrm{m}\end{array}$ & \begin{tabular}{|l}
$10-20 \mathrm{kHz}$ \\
$209209-$ \\
$116532 \Omega . \mathrm{m}$
\end{tabular} & $\begin{array}{l}20-100 \mathrm{kHz} \\
116532- \\
11999 \Omega . \mathrm{m}\end{array}$ & - \\
\hline & $\begin{array}{l}\text { Mund- } \\
\text { rabilla }\end{array}$ & $\begin{array}{l}45 \mathrm{~Hz} \\
60861 \Omega . \mathrm{m}\end{array}$ & $\begin{array}{l}1 \mathrm{kHz} \\
52069 \Omega . \mathrm{m}\end{array}$ & & $\begin{array}{l}1-20 \mathrm{kHz} \\
52069- \\
9153 \Omega . \mathrm{m}\end{array}$ & $\begin{array}{l}20-100 \mathrm{kHz} \\
9153- \\
1690 \Omega . \mathrm{m}\end{array}$ & - \\
\hline \multirow{3}{*}{ 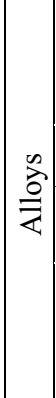 } & $\begin{array}{c}\text { Alloy- } \\
9.7\end{array}$ & $\begin{array}{l}85 \mathrm{~Hz} \\
664 \Omega . \mathrm{m}\end{array}$ & $\begin{array}{l}1 \mathrm{kHz} \\
751 \Omega . \mathrm{m}\end{array}$ & $\begin{array}{l}10 \mathrm{kHz} \\
845.2 \Omega . \mathrm{m}\end{array}$ & $\begin{array}{l}10-20 \mathrm{kHz} \\
845.2- \\
726 \Omega . \mathrm{m}\end{array}$ & $\begin{array}{l}20-100 \mathrm{kHz} \\
726- \\
456 \Omega . \mathrm{m}\end{array}$ & - \\
\hline & $\begin{array}{l}\text { Alloy- } \\
17.5\end{array}$ & $\begin{array}{l}100 \mathrm{~Hz} \\
4353 \Omega . \mathrm{m} \\
\text { Alloy }\end{array}$ & $\begin{array}{l}1 \mathrm{kHz} \\
4446 \Omega . \mathrm{m}\end{array}$ & - & $\begin{array}{l}1-20 \mathrm{kHz} \\
4446- \\
2618 \Omega . \mathrm{m}\end{array}$ & $\begin{array}{l}20-100 \mathrm{kHz} \\
2618- \\
1433 \Omega . \mathrm{m}\end{array}$ & - \\
\hline & $\begin{array}{l}\text { Alloy- } \\
30.0\end{array}$ & $\begin{array}{l}55 \mathrm{~Hz} \\
6133 \Omega . \mathrm{m}\end{array}$ & $\begin{array}{l}1 \mathrm{kHz} \\
5235 \Omega . \mathrm{m}\end{array}$ & - & $\begin{array}{l}1-20 \mathrm{kHz} \\
5235- \\
2879 \Omega . \mathrm{m}\end{array}$ & $\begin{array}{l}20-100 \mathrm{kHz} \\
2879- \\
1542 \Omega . \mathrm{m}\end{array}$ & - \\
\hline
\end{tabular}

The obtained electrical signatures can be divided into four main electric stages: (i) Pre-saturation electrical stage or "building up energy stage", in which the measured electric resistivity usually increases with one or more peaks, due to some abruptly behavior; (ii) threshold stage or "steep stage", in which the material attains the saturation stage and the measured electrical resistivity starts to decrease rapidly, (iii) transitional stage; and (iv) steady stage, in which increasing the applied AC frequency does not results in large change of electrical resistivity which becomes more or less steady or slightly decreasing with frequency increase. Reaching the steady stage may be explained by reaching the saturation stage of the electric charges accumulated at the surface of the studied sample. 

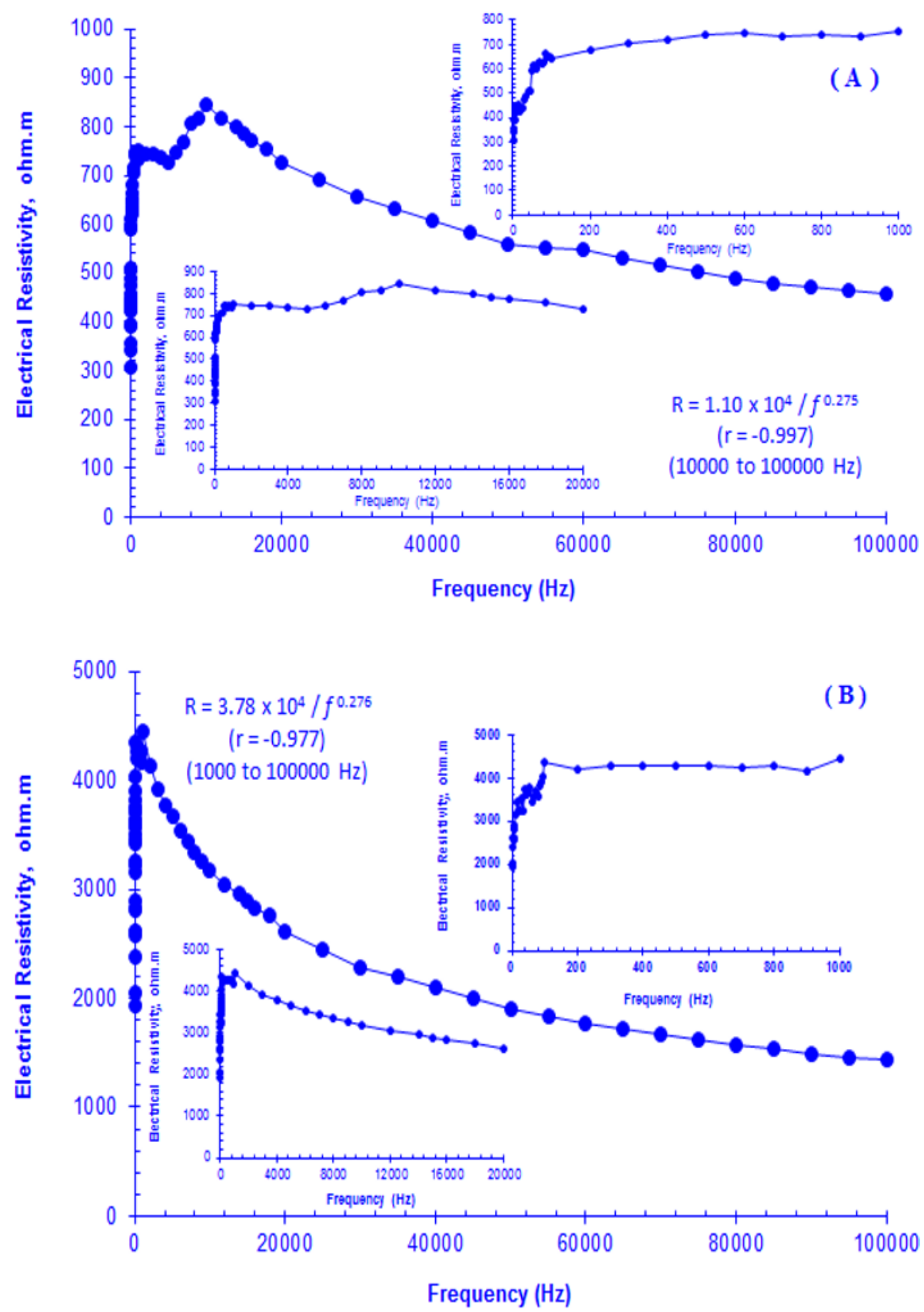

Fig. 1. Caption on next page. 


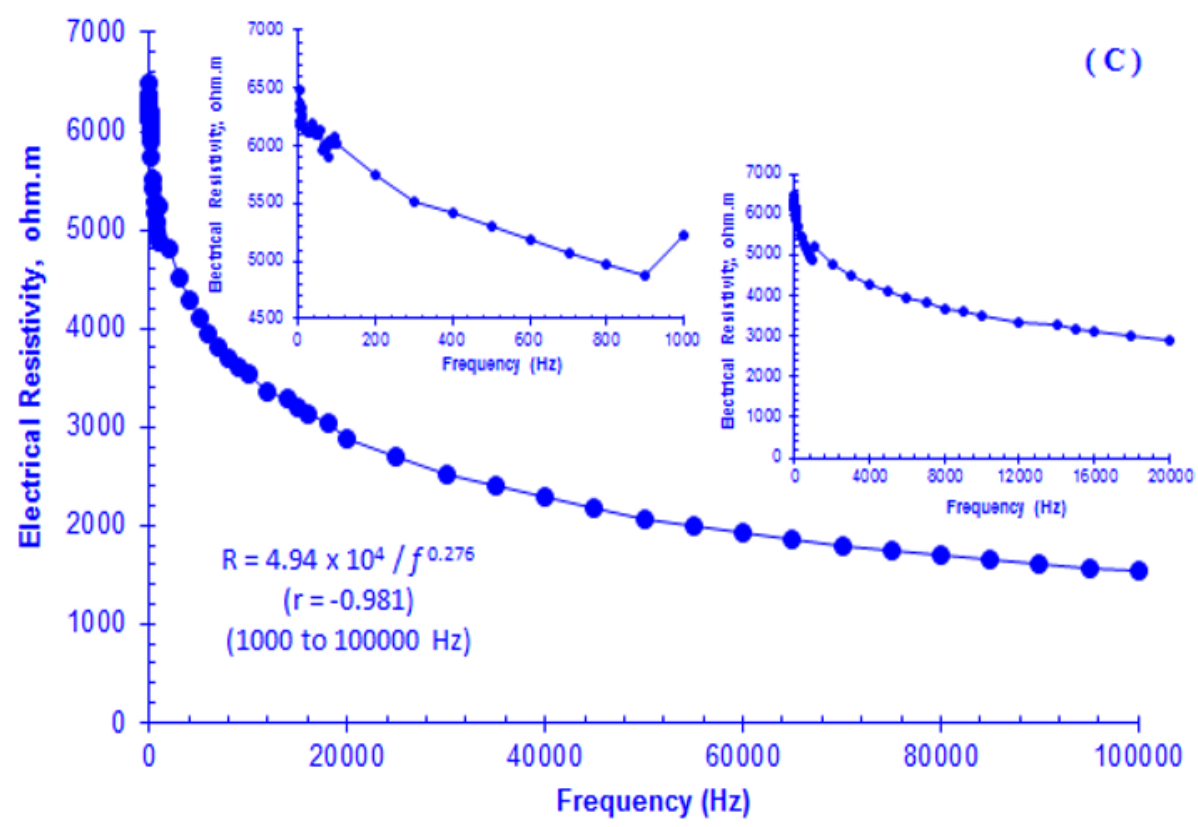

Fig. 1. Electrical signature, electrical resistivity versus $\mathrm{AC}$ frequency, for the studied Fe-Ni models: (A) $9.7 \% \mathrm{Ni}$, (B) $17.5 \% \mathrm{Ni}$, and (C) $30.0 \% \mathrm{Ni}$.

\subsubsection{The prepared models}

The Fe-Ni alloys, in general, are characterized by a relatively low resistivity, very low slope values and absence of the steady state up to $100 \mathrm{kHz}$ (Fig. 1, Table 3). Their electrical signatures seem to be dependent on the Ni content, with an increase of resistivity with Ni content at a given frequency. For the alloy having low Ni content $(9.7 \%)$, three peaks are observed in the presaturation stage, at $85 \mathrm{~Hz}, 1$ and $10 \mathrm{kHz}$ (Fig. 1A). The steep stage extends from 10 to $20 \mathrm{kHz}$ with steep slope $(0.012 \Omega . \mathrm{m} / \mathrm{Hz})$, whereas the transitional stage has more gentle slope $(0.003 \Omega . \mathrm{m} / \mathrm{Hz})$.

Similar to the electrical signature of the $9.7 \%$ Ni-platelet, two electrical peaks are assigned at frequencies less than $100 \mathrm{~Hz}$ and at $1 \mathrm{kHz}$ values for the 17.5 and $30.0 \%$ Ni-alloys (Fig. 1B, C). Therefore, the steep stage starts early at $1 \mathrm{kHz}$ and extends up to $20 \mathrm{kHz}$. The slope of the resistivity-frequency curve for the 17.5 Ni-alloy at its steep stage equals $0.085 \Omega . \mathrm{m} / \mathrm{Hz}$, whereas it increases to $0.107 \Omega . \mathrm{m} / \mathrm{Hz}$ for the $30.0 \mathrm{Ni}$-alloy. The transitional stage of these meteorites is characterized by a slope equal to 0.014 and 0.016 $\Omega . \mathrm{m} / \mathrm{Hz}$ for the $17.5 \mathrm{Ni}$-alloy, respectively. 

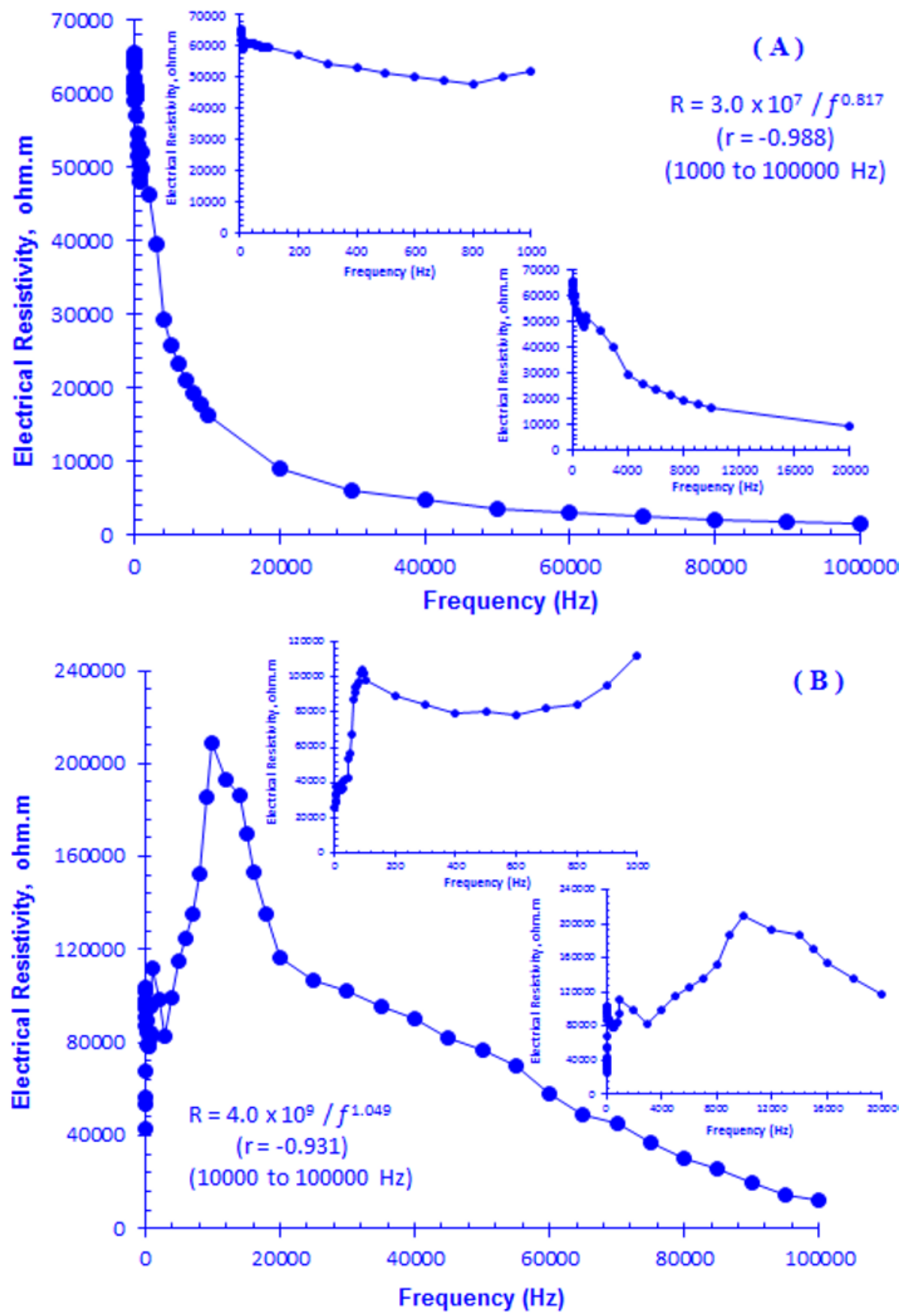

Fig. 2. Electrical signature of the studied iron meteorites: (A) Mundrabilla meteorite, and (B) Gibeon meteorite. 


\subsubsection{Iron meteorites}

The electrical behaviors of the iron meteorites are mostly characterized by lower resistivity values (Table 3 ) due to their high metal contents, although they are more resistive than the artificial alloys.

For Mundrabilla meteorite, the electric resistivity starts with very high values at $1 \mathrm{~Hz}$ and then decreases rapidly till $45 \mathrm{~Hz}$, at which an electrical signature can be described (Fig. 2A). The saturation history starts early, at $45 \mathrm{~Hz}$; then values in the steep stage (of $2.15 \Omega . \mathrm{m} / \mathrm{Hz}$ slope), and drops from $52069 \Omega . \mathrm{m}$ at $1 \mathrm{kHz}$ down to $9153 \Omega . \mathrm{m}$ at $20 \mathrm{kHz}$. The post-saturation transitional stage is characterized by a gentle slope (slope $=0.128 \Omega . \mathrm{m} / \mathrm{Hz}$ ) up to $100 \mathrm{kHz}$. No steady stage can be assigned in the studied frequency range.

The Gibeon meteorite, on the other hand, shows relatively high electric resistivity values, which may be attributed to its complex internal structure and texture as inferred from the SEM and EDX techniques. Its electrical signature presents three peaks in the pre-saturation stage at $90 \mathrm{~Hz}, 1 \mathrm{kHz}$, and $10 \mathrm{kHz}$ (Fig. 2B). The peaks are followed by a steep stage extending from 10 up to $20 \mathrm{kHz}$ (of slope $9.57 \Omega . \mathrm{m} / \mathrm{Hz}$ ) that characterizes the electrical behavior of Gibeon meteorite. A transitional stage is between 20 and $100 \mathrm{kHz}$ (slope $=1.31 \Omega . \mathrm{m} / \mathrm{Hz}$ ) with no steady stage.

\subsubsection{Stony meteorites}

The electrical signature for the NWA 869 meteorite (L3-6 Chondrite) is characterized by the formerly mentioned four stages. The first, pre-saturation stage is characterized by three electric peaks at relatively low frequencies: 8 , 40 , and $80 \mathrm{~Hz}$ (Fig. 3A). The second, "steep stage" starts at $1 \mathrm{kHz}$ with verysteep slope $(108.3 \Omega \mathrm{m} / \mathrm{Hz})$, whereas the third, "transitional stage" starts later, from 1 to $20 \mathrm{kHz}(1.53 \Omega \mathrm{m} / \mathrm{Hz})$. The last, fourth, "steady stage" is characterized by very low slope $(0.045 \Omega . \mathrm{m} / \mathrm{Hz})$.

The NWA 7629 meteorite (L5 Chondrite) shows electrical behavior similar to the NWA 869 but with only one peak at $60 \mathrm{~Hz}$ in the pre-saturation stage (Fig. 3B). The other three stages can be described as: (i) steep stage from $80 \mathrm{~Hz}$ to $1 \mathrm{kHz}$ with very steep slope $(141.2 \Omega \mathrm{m} / \mathrm{Hz}$ ), (ii) transitional stage from 1 to $20 \mathrm{kHz}(1.32 \Omega . \mathrm{m} / \mathrm{Hz})$ and (iii) last, steady stage with very low slope $(0.021 \Omega . \mathrm{m} / \mathrm{Hz})$.

Ghubara meteorite (L5 Chondrite) has a mixed signature between the signatures of NWA 869 ((LL6/7 Chondrite)) and the NW 7629 (LL5 Chondrite) but with more abrupt behavior, more extended pre-saturation stage and absence of the second, steep stage (Fig. 3C). Three electrical peaks are noticed at $100 \mathrm{~Hz}, 12 \mathrm{kHz}$, and $18 \mathrm{kHz}$. The transitional zone (18$40 \mathrm{kHz})$ is characterized by relatively gentle slope $(17.54 \Omega . \mathrm{m} / \mathrm{Hz})$, whereas the steady stage has a negligible slope $(0.14 \Omega . \mathrm{m} / \mathrm{Hz})$. 


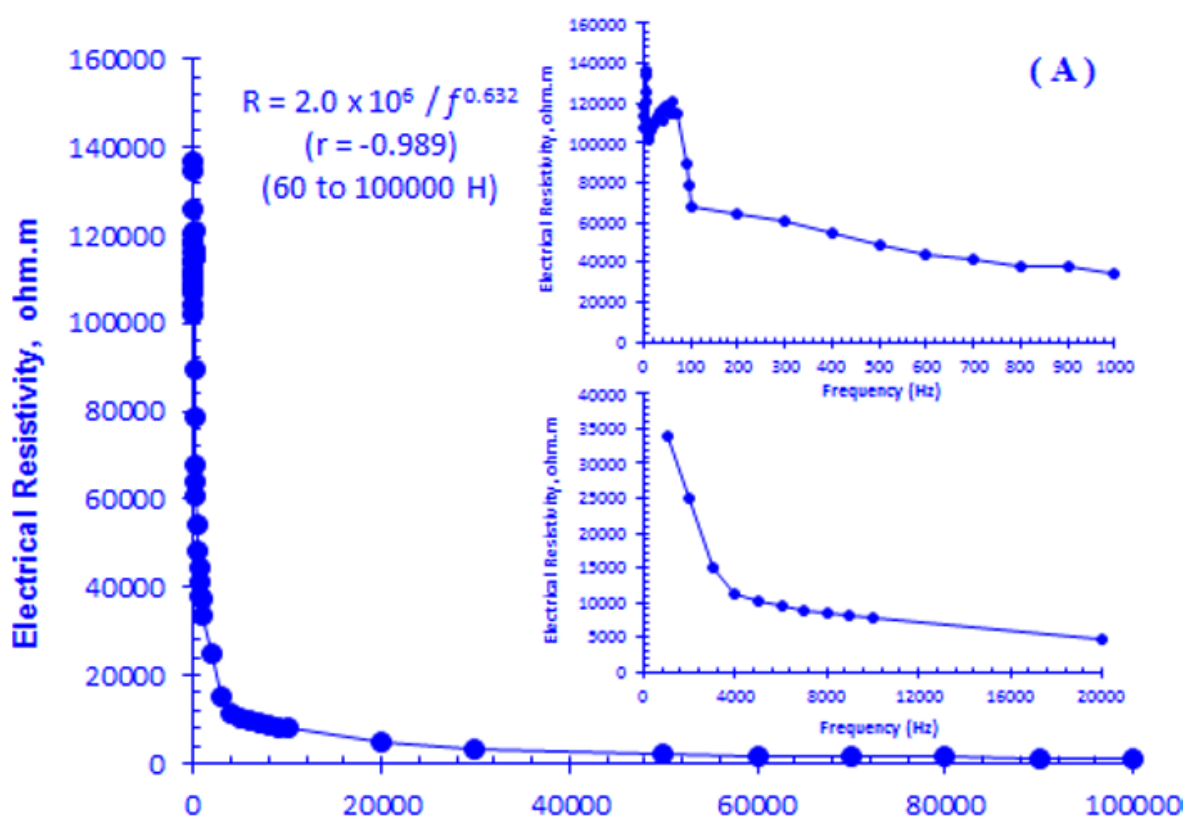

Frequency $(\mathrm{Hz})$

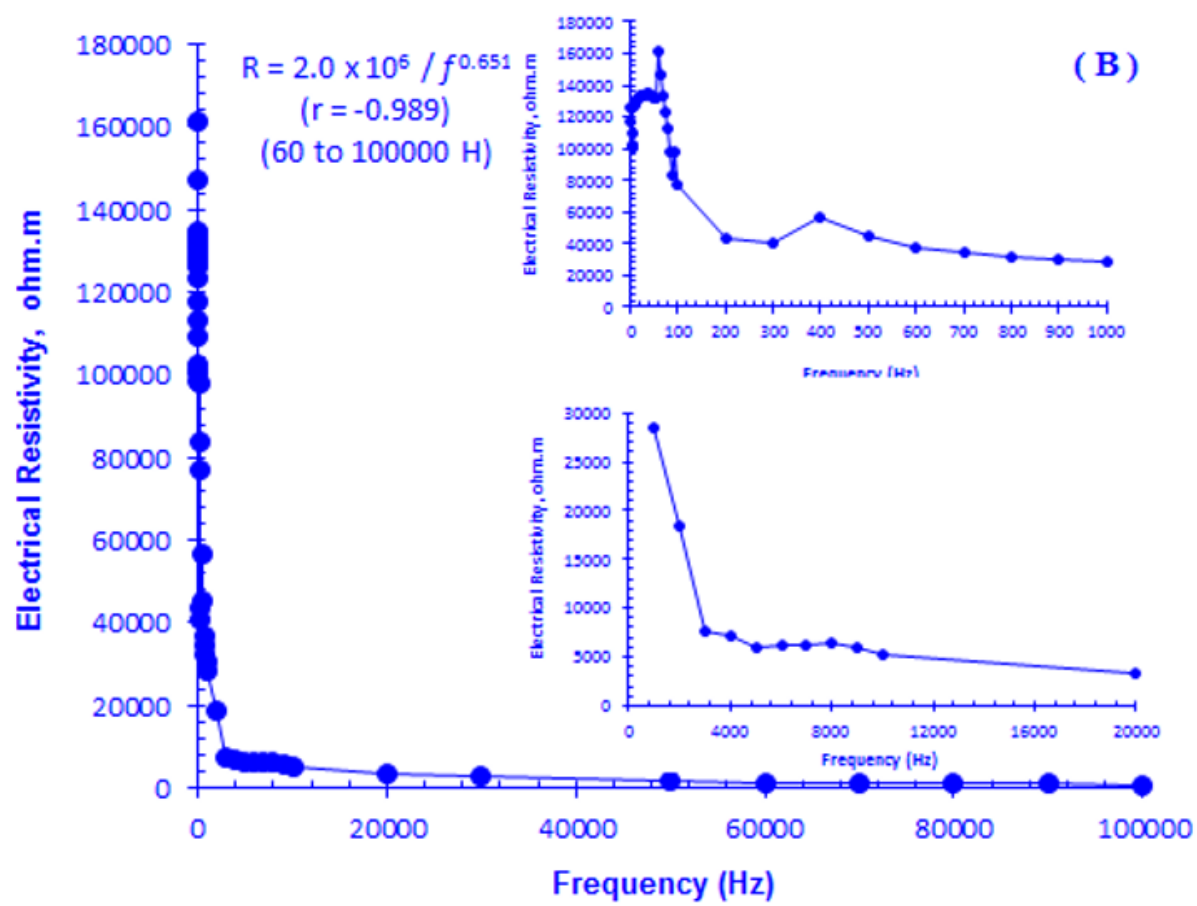

Fig. 3. Caption on next page. 


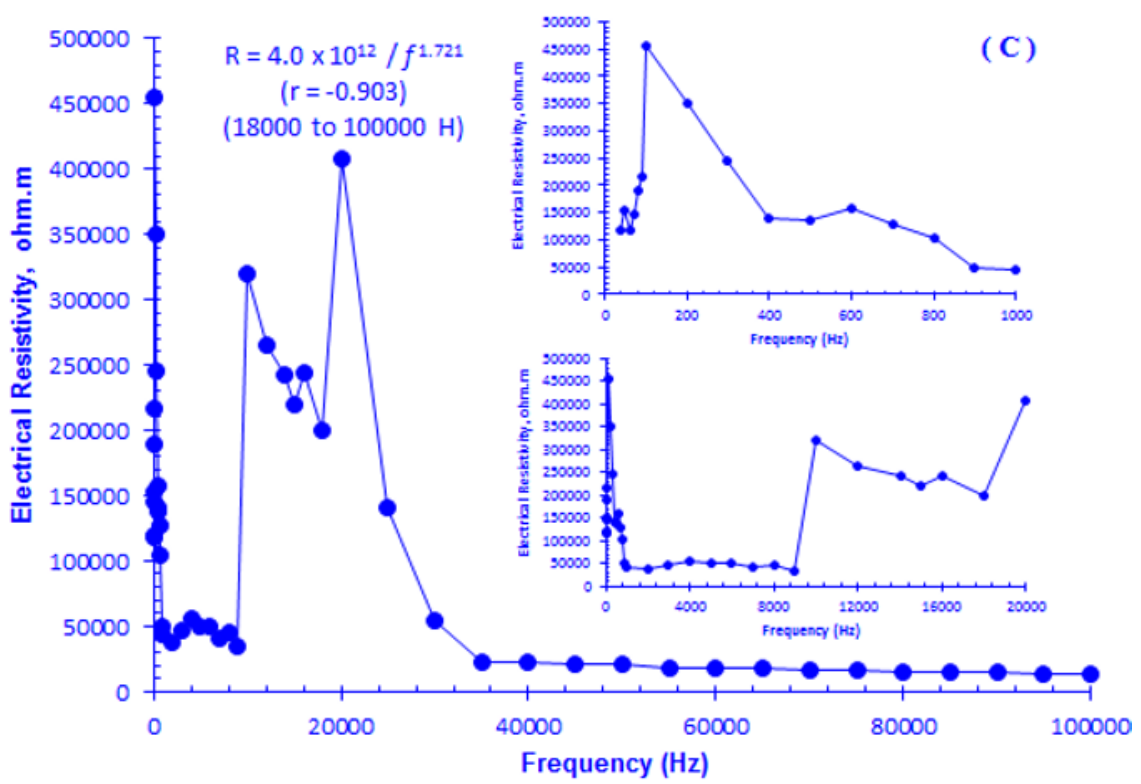

Fig. 3. Electrical resistivity versus AC frequency "electrical signature" for the studied stony meteorites: (A) NWA 869, (B) NWA 7629, and (C) Ghubara meteorite.

\subsection{SEM studies and EDX analysis}

It is known that the electrical behavior of the rocks depends on two components: the electrolyte filling the pore spaces, and the conductivity of the solid components of the material. In case of impermeable or dry solid materials, the electric behavior is mostly raised from the conductive components of the solid phase. Consequently, the electric behavior of the studied meteorites (being dried and of low porosity) depends on their mineralogical components.

For the prepared meteorites and reference models, the SEM studies supported with EDX technique ensured the accuracy of the proposed composition with slight deviation for Alloy-1 $(9.7 \% \mathrm{Ni})$. The EDX analysis of Mundrabilla meteorite seems to be comparable in composition to Alloy-3 (Table 1). The Fe-Ni composition of the prepared alloys gave rise to development of the octahedral texture for the alloys, as shown in Fig. 4, with increasing the Ni content. The presence of some micro vugs increased the pore volume, as indicated from the porosity measurements using the He injection technique. The observed micro vugs are mostly formed due to capturing of some air bubbles during the melting and processing of the alloys. The SEM microphotographs of the studied meteorites Mundrabilla, NWA 869, and NWA 7629 are shown in Fig. 5 with the octahedral structure, indicating the Fe-Ni composition of Mundrabilla sample. The heterogeneity in composition 


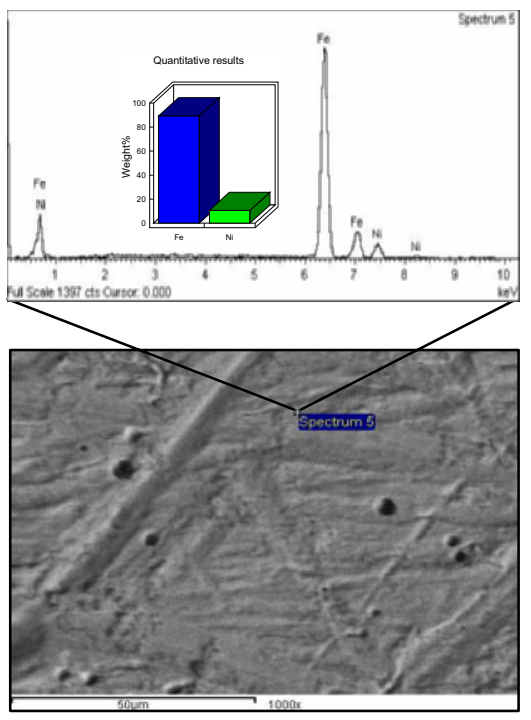

Alloy-1 $(9.7 \% \mathrm{Ni})$

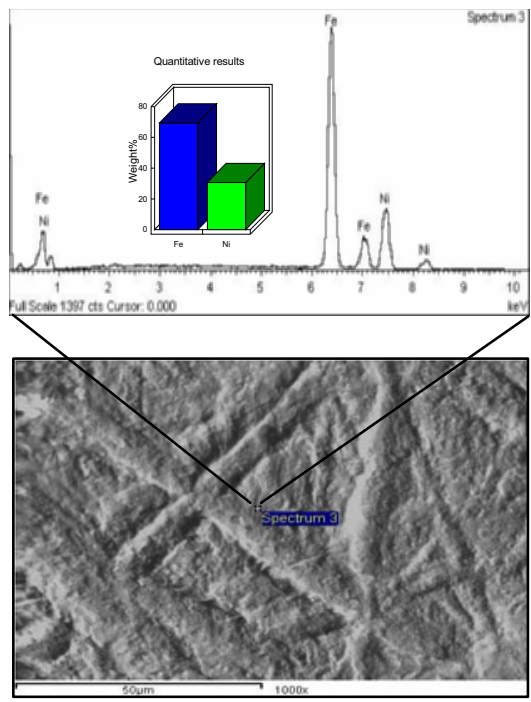

Alloy-3 (30.0\% Ni)
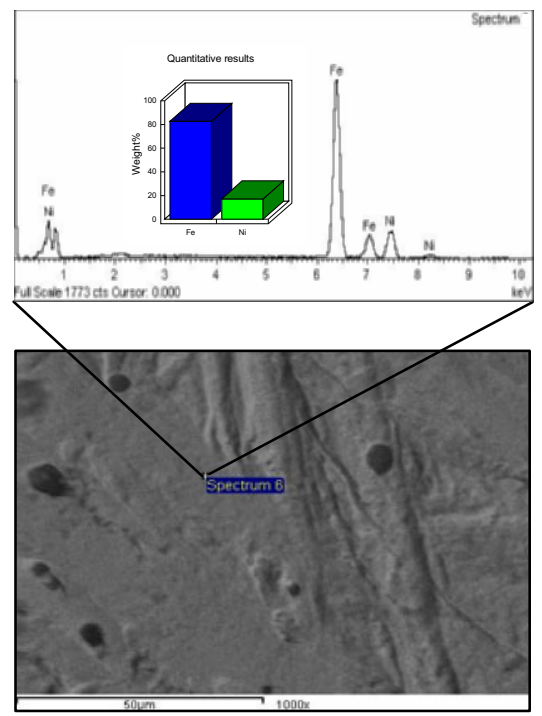

Alloy-2 (17.5\% Ni)

Fig. 4. SEM photomicrograph accompanied with the results of the EDX analysis which ensure the chemical which ensure the chemical composition of the prepared alloys showing the octahedral structure of the prepared alloys.

has been shown for the other samples with two main components indicated for NWA 869; stony and sulphide patches. The composition of the NWA samples is mostly iron silicates, with some other minor components (Table 1). The sulfide phase of NWA 869 is composed mostly of iron sulfide and iron carbide (Fig. 5, Table 1). Using the SEM indicates the presence of some factures in the micro scale $(0.65 \mu \mathrm{m})$, as shown in Fig. 6. 


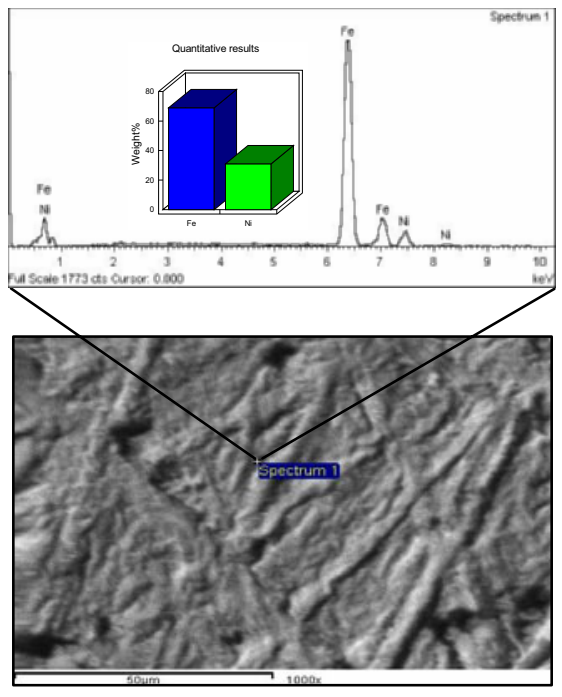

(A) Mundrabilla
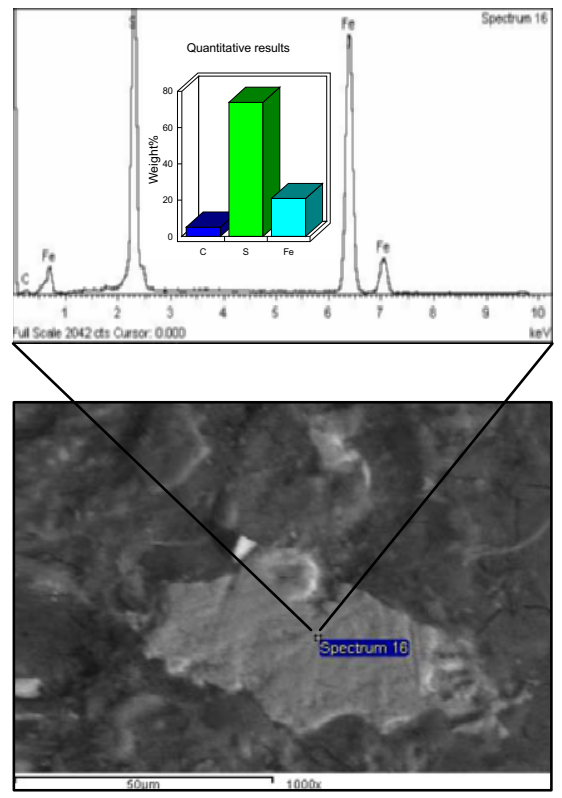

(C) NWA 869 (sulphide phase)

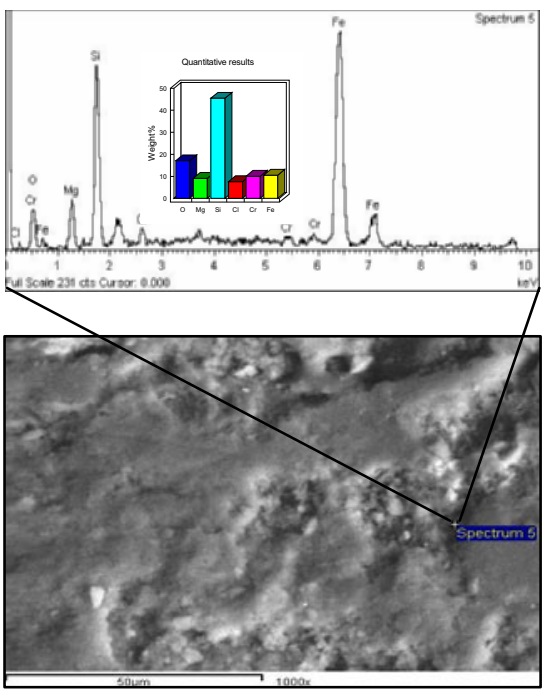

(B) NWA 7629
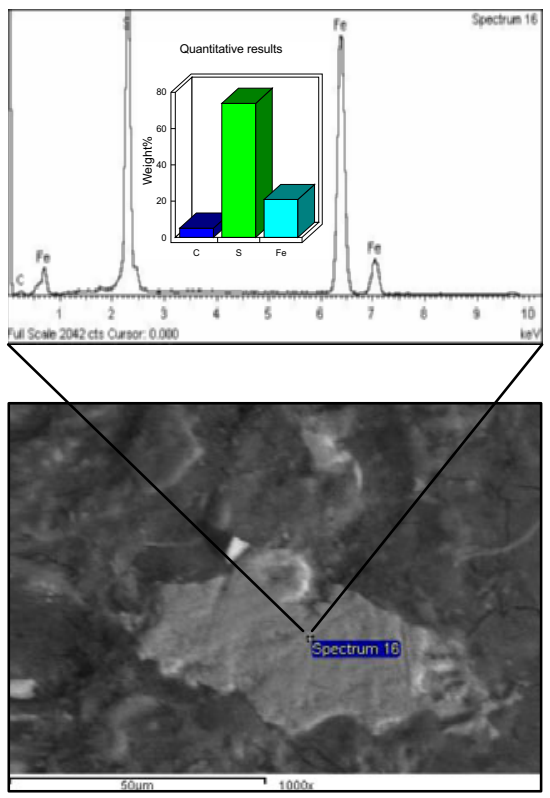

(D) NWA 869 (stony phase)

Fig. 5. SEM photomicrograph accompanied with the results of the EDX analysis for the studied meteorites indicates the octahedral structure of Mundrabilla and the iron silicate composition of the chondrites. The presence of sulphide phase for NWA 869 sample is indicated as bright patches. 


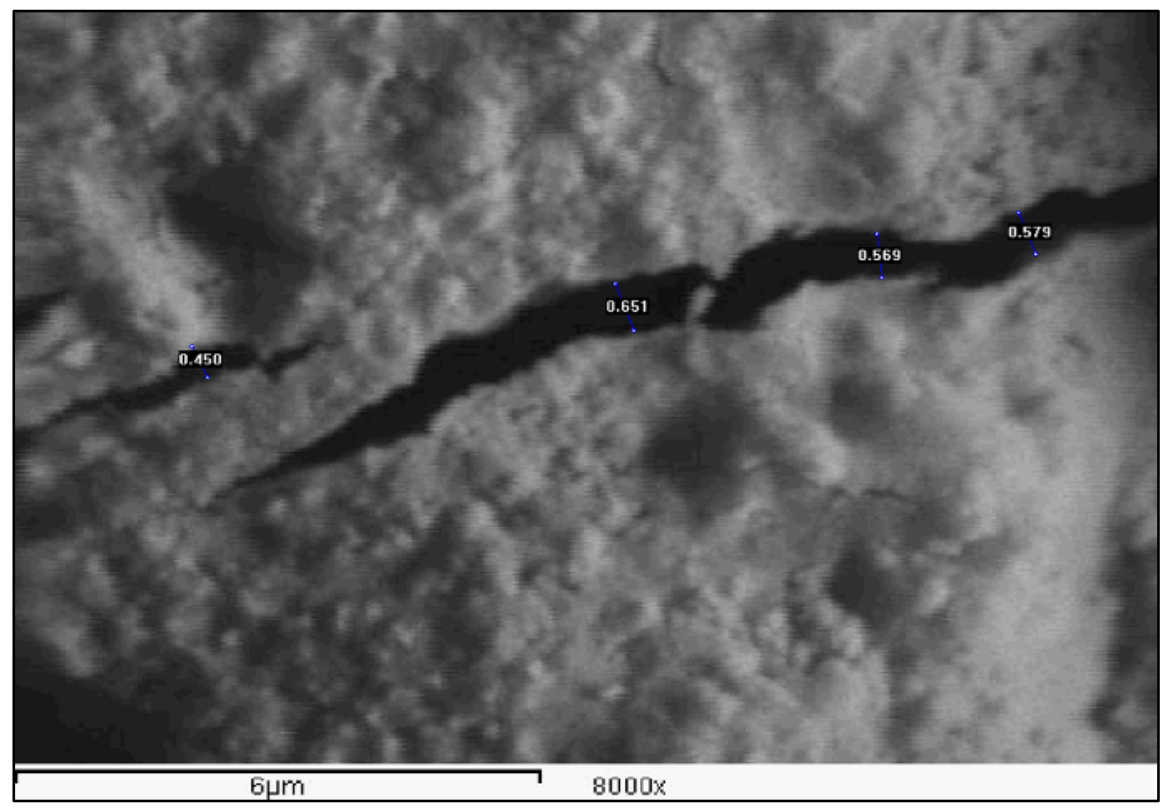

Fig. 6. SEM photomicrograph indicates the presence of some micro fractures of wideness not more than $0.65 \mu \mathrm{m}$, NWA 869 sample.

\subsection{Grain density and porosity}

Grain density and porosity of the studied meteorites are mostly controlled by their mineralogical and chemical composition, as well as by the intensity of shock, metamorphism, melting, and sometimes recrystallization. The intensity of these processes may reduce the final porosity by about $50 \%$ of the original porosity (Christie et al. 1973, Kieffer and Simonds 1980). Grain density is a useful tool for distinguishing the terrestrial rocks from meteorites. Most meteorites are ordinary chondrites, and have a grain density in the range of 3.0 to $3.7 \mathrm{~g} / \mathrm{cm}^{3}$, which is denser than most terrestrial rocks. Iron meteorites are even denser; in the range of 7.0 to $8.0 \mathrm{~g} / \mathrm{cm}^{3}$. For the present study, bulk and grain densities as well as porosity were measured for 3 meteorites samples as well as for the three alloys (Table 2). 15 measurements have been conducted for each sample and the average is calculated. The grain density of the studied samples show very close values $\left(3.49 \mathrm{~g} / \mathrm{cm}^{3}\right)$ for the $\mathrm{L}$ meteorites and close values for the metal alloys and Mundrabilla $\left(7.78-7.98 \mathrm{~g} / \mathrm{cm}^{3}\right)$. Similarly, the bulk density values are similar for the two groups; the stony and the iron meteorites. Porosity values for the studied samples are very low, in the range $2.2-2.9 \%$, whereas the prepared alloys show relatively rare defects during the preparation. 


\section{GENERAL DISCUSSION}

The environment of the meteorites accumulation, whether it is hot or cold, will determine their weathering history (Bischoff and Geiger 1995, Bland et al. 1996, Stelzner et al. 1999, Welten 1999, Lee and Bland 2004).

In ordinary chondrites, Fe-metal and Fe-sulfide are especially susceptible to weathering, and the transformation into rusting minerals involves a huge specific volume increase, that results in expansion cracking of the sample (Gooding 1986b).

Among meteorites, porosity tends to be reduced due to filling by the weathering products at the early stage of weathering, resulting in meteorites having lower porosities than those discovered immediately after a fall (Consolmagno et al. 1998). This stage proceeds rapidly at first, until the weathering product, filling the pore spaces, reduces the flow of water and oxygen into the meteorite (Gooding 1986a).

Flynn (2004) has further considered the effect of porosity on the mechanical strength, and identifies an "atmospheric filter", arguing that meteorites with high porosity are likely to preferentially undergo fragmentation during atmospheric ablation.

Measuring porosity of the studied meteorites and iron meteorites indicates the presence of pore spaces of negligible percentage, mostly not greater than $3 \%$. On the other hand, porosity of the Fe-Ni models is slightly higher than that of the studied meteorites (Table 2) due to the presence of some gas bubbles during manufacturing and processing.

Wilkison and Robinson (2000) found a lack of correlation between the meteorite group and porosity, but they observed a strong correlation between porosity and bulk density for the ordinary chondrites. This is suggestive of the possibility that it is the porosity that controls the bulk density, at least within ordinary chondrites.

For the present study, porosity as well as the bulk and grain density were precisely measured using the helium pycnometer with very low standard variation values of three measurements for each parameter. The relatively high grain density data of the iron meteorites are reasonable, due to the higher grain density of nickel content $\left(\rho_{g}=8.908 \mathrm{~g} / \mathrm{cm}^{3}\right)$ with respect to iron content $\left(\rho_{g}=7.874 \mathrm{~g} / \mathrm{cm}^{3}\right)$. This is confirmed by a significant correlation between Ni content and average grain density (Fig. 7). The dependence of porosity on bulk density, as well as the studied relationship between the grain density and the Ni content, implies good relationships between porosity, density (bulk and grain), Ni content, and the measured electric resistivity values.

Several distinct types of porosity can be distinguished during the study of the meteorites. The best known types of porosity observed within the me- 


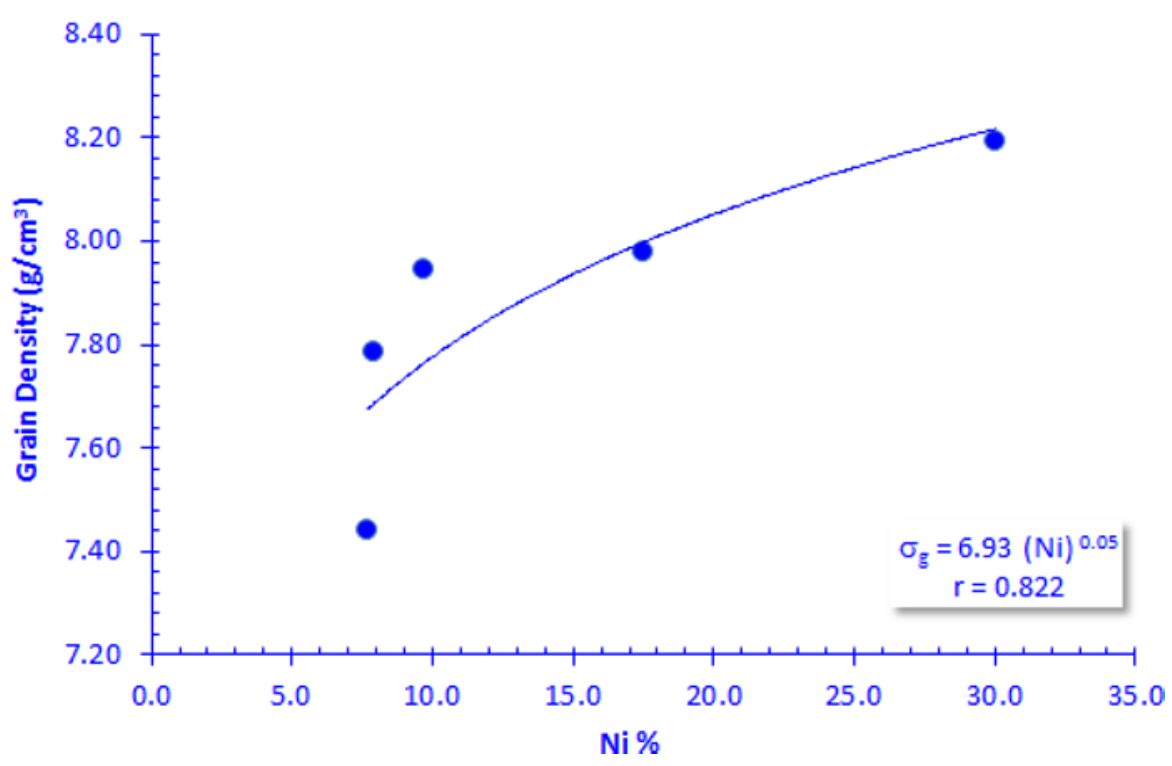

Fig. 7. Plot of Ni\% versus the grain density $\left(\sigma_{g}\right)$ for the studied iron meteorites and the prepared alloys.

teorites are the micro cracks and vugs. Despite the presence of open and closed micro cracks, as well as micro vugs within the meteorites, the latter two types of pore spaces cannot be measured by the standard He pycnometer technique. Only the open cracks can be measured by the He injection technique.

The studied types of pore spaces detected within the present meteorites are mostly of different origins, due to the meteorite's crystallization and compaction history (determined as primary porosity), its collisional history (secondary porosity), and its terrestrial residency time. In the final case, for example, one might expect the porosity to decrease with time, due to the growth of secondary minerals, weathering within the pore space (Coulson et al. 2007). Based on the studied porosity types of the present meteorites, two origins are proposed for these pore spaces; the crystallization during cooling and collisional origin on shocking with the Earth's surface.

\subsection{Crystallization origin of porosity within meteorites}

The SEM studies of the present meteorites supported with the EDX technique showed a well developed octahedral structure of the Mundrabilla (Fig. 5), which can be attributed to its high Ni content (31.05\%, Table 2). The interior structure of the Mundrabilla is characterized by the presence of some micro pore spaces, as shown in Fig. $5 \mathrm{~A}(\varnothing \leq 3.25 \%)$. The origin of 
micro vugs may be attributed to some nitrogen or noble gas bubbles that have been trapped inside the octahedral structure during melting and cooling.

The origin of the nitrogen " $\mathrm{N}$ " content in the iron meteorites is unclear. The "N" content of metal condensing from the solar nebula should be very low $(\approx 0.1 \mathrm{ppm}$ or less) for reasonable pressure-temperature (PT) conditions (Fegley 1983). This indicates that, the "N" must have been acquired by the metal at a later stage.

Trapped noble gases have traditionally been subdivided based on their origin into "solar" and "planetary" varieties (Signer and Suess 1963). Early workers called both the solar and the planetary varieties "primordial". This term implies that the gases had been incorporated very early during the formation of the solar system, either in precursor solids of meteoritic materials or during the formation of chondrites and their parent bodies (Wieler et al. 2006). Indeed, observations of trapped noble gas components in iron and stony meteorites are rare, in agreement with the high temperatures probably experienced by these meteorites. Trapped gases were mainly found in silicate inclusions of IAB iron meteorites, often associated with C (Bogard et al. 1971, Crabb 1983, Mathew and Begemann 1995, etc.), and in the silicates of the pallasite Brenham.

For the studied Mundrabilla iron meteorite, Weinke (1977) showed the presence of carbon " $\mathrm{C}$ "; its content reaches up to $1.5 \%$. In addition, the applied EDX technique evidenced that the "C" content reaches up to 5\% for both the iron and sulphide phases of the NWA 869 meteorite (Table 1). This gives up a weight for the origin of the micro vugs of the present meteorites, as a result of noble gas trapping, not due to the trapping of $\mathrm{N}$ content which is completely absent for the present meteorites.

\subsection{Collisional origin of porosity within meteorites}

Pesonen et al. (1997) stated that the porosity of L chondrites decreases reasonably and consistently with increasing shock index, while the $\mathrm{H}$ chondrites show no apparent tendency for the porosity to decrease with increasing shock index. Consolmagno et al. (1998) appropriately said: "clearly, shock can reduce the porosity of some meteorites, but there is no way to predict a priori, which meteorites have or have not had their porosity reduced in this manner".

On the other hand, Strait and Consolmagno (2004) concluded that the micro-crack porosity observed in the meteorites may have its origin in a process common to all meteoritic material, such as impact and ejection of the meteorite. Unfortunately, if this is the case, then the observed meteorite (micro-crack) porosity may tell us little about the early history of meteorites. 
Coulson et al. (2007) appropriately mentioned that, for shock pressures between $\sim 40$ and $50 \mathrm{GPa}$, the porosity is found to vary between within poor to negligible values of 2 and $11 \%$. At these high shock pressures, the shock opening is accompanying with a null effect (many new cracks and fissures are created and in the same time some of the primary cracks are closed.

Applying the SEM technique has also evidenced the presence of micro cracks in some samples, as shown in Fig. 6. Despite the successful application of SEM in the detection of micro cracks in meteorite porosity studies, some cautions must be taken into considerations, where it is very important to check the origin of these micro cracks which might have originated during sample preparation. If these micro cracks are not open and limited to the sample interior (Fig. 6), it would seem likely that, they have not been created during sample preparation. Another proof for the origin of theses micro cracks is the presence of weathering material within such cracks.

The nature of micro cracks provides information on another origin for the measured porosity, originated by the distortion of compacted meteorites, due to shock effects relating to collisions with the Earth's surface, which may create some defects in the solid matrix at the high temperature generated due to the fast and strong shocking.

\subsection{Chemical composition of the studied meteorites}

Supporting the SEM imaging by EDX technique confirmed that the studied chondrites are mostly composed of silicates with some iron and chromium content (Table 1). The studied Mundrabilla meteorite is similar in its chemical composition to the prepared model-3 with dominant Ni content reaching up to $31 \%$ (Table 1), which is responsible for forming the octahedral structure in Mundrabilla meteorite. Interestingly, secondary mineral inclusions of calcite $(\mathrm{Ca}=6.34)$ and magnesite $(\mathrm{Mg}=12.23 \%)$ have been found in the NWA 869, while the NWA 7629 contains some magnesite content $(\mathrm{Mg}=9.14 \%)$. The origin of these inclusions is mostly due to crystallization in the first stages of meteorite formation. Two phases, sulfide and stony phases (Fig. 5C and D), were detected in the NWA 869 meteorite using the SEM and EDX techniques, which may explain the variation in chemical composition and the physical behavior of the studied NWA 869.

\subsection{Electrical properties of the studied meteorites}

A decrease in the electrical resistivity " $R$ " is expected with increasing electric frequency " $f$ ", where the electric frequency controls the movements of the electric charges through the material under study and increases the electric current intensity. A disturbance in this behavior is noticed before a definite frequency value which is diagnostic for each material; therefore, the 
electrical behavior has to be characterized for each material. This diagnostic behavior is based on the mineralogical and chemical compositions, as well as the internal structure (the pore and solid fabrics) of these materials.

At frequencies lower than this frequency, the electric charges and energy level seem to be lower than the saturation. For the present study, we tend to call it the threshold saturation frequency.

The electrical resistivity values in the pre-saturation stage are usually unsteady and abruptly changed from medium or relatively low resistivity to high resistivity at a threshold saturation frequency. Some secondary thresholds may be detected before the main threshold saturation. At higher frequencies, the electric energy is capable of enhancing the electric current intensity and, therefore, it introduces a well-defined, steeply or gently decreasing electrical resistivity with increasing frequency (Figs. 1-3).

\subsubsection{The prepared models}

The dependence of the electric resistivity " $R$ " of the studied stony meteorites on the applied electric frequencies " $f$ " is mostly characterized by inversely proportional relationship between " $R$ " and " $f$ " in the post-saturation level of energy, as shown in Fig. 1. This electrical behavior "electrical signature" of the prepared models has been studied and traced (Fig. 1) to be compared with the studied meteorites, as a trial to predict their chemistry and petrography. The increasing nickel content gave rise to a simpler behavior, with fewer peaks (Table 3) in the pre-saturation stage, while at the lowest nickel content, a much more complicated electric behavior is noticed. Similar to the studied meteorites, the electrical behaviors of these models are non-systematic before the saturation level. So a statistical processing has been applied to the post-saturation stages only.

\subsubsection{Stony meteorites}

The electric behavior could be distinguished into four stages, comparable to the applied electric frequencies and therefore they seem to be energy levels. At the pre-saturation stage, an abrupt behavior is obtained where the applied energy level is relatively low to control the electric behavior of the mineralogical components of the measured samples. At energy levels in the saturation and post-saturation levels, the electric behavior can be traced.

The similarity between both NWA 869 and NWA 7629 samples, in their grain fabrics as well as their chemical composition (Table 1) leads to more or less similar electric behavior with the same frequency peaks (Fig. 3A and B). The stony and sulfide phases (Fig. 5C and D), as observed from the SEM studies supported with the EDX technique (Table 1), is better defined for sample NWA 869, than that for sample NWA 7629. The well defined metallic phase in sample NWA 869 may be responsible for lowering the electric 
resistivity values in comparison to sample NWA 7629 through different energy saturation stages.

The mixed electrical signature of the Ghubara sample and its more complicated electric behavior indicated that the presence of three peaks in the pre-saturation stage may be attributed to the grain fabric of the studied sample, which can be distinguished into two very well defined components. This distinguishable fabric caused more complicated and abrupt electric behavior, with the saturation stage reached at much higher frequency of $18 \mathrm{kHz}$.

\subsubsection{Iron meteorites}

Due to their high metal content, the iron meteorites are expected to be characterized by low electric resistivities. On the contrary, the Gibeon meteorite is characterized by a much more complicated signature, due to its internal structure, by relatively high resistivity and by two peaks in the pre-saturation stage with a well-defined third peak, threshold energy saturation level, at much more higher frequency, $10 \mathrm{kHz}$ (Fig. 2A). The electric behavior of Mundrabilla, on the other hand, seems to be much simpler, with the saturation frequency detected at very low frequency of $45 \mathrm{~Hz}$ (Fig. 2B). Therefore, the saturation frequency seems to be an indicator for the homogeneity of the internal structure, i.e., the simplicity or complexity of the electrical signature of the studied meteorite is an indicator for the simplicity or complexity of the internal structure.

To model the electrical resistivity-frequency relationship, a number of equations were introduced to calculate " $R$ " in terms of " $f$ ", as shown in Fig. 2. Due to the abrupt behavior in the pre-saturation stage, and the systematic behavior after this level of energy, the introduced equations were applicable for the post-saturation stages only.

Characterizing the electric behavior of the iron and stony meteorite, our attention was drawn toward some critical frequency peaks, the most important ones being at 1 and $20 \mathrm{kHz}$; at one of them the energy saturation of the samples has to be reached. The presence of different frequency peaks in the pre-saturation stage indicates frequent accumulation and discharge of electrons at these peaks, until the defined frequency peak, "the threshold saturation frequency", is reached. At that level of energy saturation, the electrons accumulation are consistent. Therefore, the electric resistivity tends to decrease abruptly till reaching the steady state, as in the case of stony meteorites. On the other hand, the iron meteorites have no steady state in the applied range of frequency until $100 \mathrm{kHz}$, but decrease in consistency.

So, one important property, which can differentiate between the two types of meteorites is the presence or absence of the steady stage. Another criterion is the saturation frequency, which can be reached earlier (mostly at 
$1 \mathrm{KHz}$ ) for the iron meteorites than the stoney meteorites (mostly at $20 \mathrm{KHz})$.

\subsection{Dependence on Ni content}

A comparison between the electric behavior of the prepared models and that of the studied iron and stony meteorites indicates a comparable behavior between the first Fe-Ni model $(\mathrm{Ni}=9.7 \%)$ and Gibeon $(7.7 \% \mathrm{Ni})$. On the other hand, a comparable behavior can be established between the signature of Mundrabilla $(31.05 \% \mathrm{Ni})$ and both the second and third models (17.5 and $30 \% \mathrm{Ni}$ content, Table 1). These comparable electrical signatures indicate the ability of predicting the chemical composition of the studied meteorites by comparison with the prepared models. The chemical composition of the Gibeon indicates relatively low Ni content, less than $10 \%$ (comparable to the first model), whereas the nickel content of the Mundrabilla indicates relatively high Ni content, around 30\% (comparable to both the second and third models). The electrical signatures of the stony meteorites, though they seem to be relatively simple, are not comparable to the prepared models.

Therefore, the present study introduces the $\mathrm{Ni}$ content of meteorites as a critical factor controling the complexity of the electric behavior and may be estimated relatively as low or high content, using their electrical signature. However, the present study is considered as a preliminary study to characterize the electrical behavior of meteorites and has to be enhanced by further similar studies. So, additional electric and petrophysical studies on more meteorite samples are recommended.

The present study introduces the electrical signature concept as a quick and simple method to classify meteorites. Once we have a sample with two parallel smooth surfaces, it takes just few minutes to trace its electrical signature and, therefore, to predict its $\mathrm{Ni}$ content in comparison to the presently prepared Ni-Fe models.

\section{CONCLUSIONS}

Plotting the electric data (electric resistivity versus the applied frequencies) for the studied iron and stony meteorite samples indicates a characteristic behavior "electrical signature" which is diagnostic for the different meteorite samples. Complexity or simplicity of that electrical signature is based mostly upon the meteorite type and its nickel content. The complexity of the signature is mostly traced at a defined frequency called saturation frequency (between 1 and $20 \mathrm{KHz}$ ). At frequency less than that diagnostic electrical frequency of energy saturation, one to three peaks can be traced, while, after that, the electrical signature can be differentiated into three stages: (i) abrupt drop and steep stage, (ii) transitional stage, and (iii) steady stage. The steady 
stage can be reached early for the stony meteorites, whereas may be reached later than $100 \mathrm{KHz}$ for the iron meteorites.

Comparison of the obtained electrical signatures with some prepared $\mathrm{Fe}-$ $\mathrm{Ni}$ models, of different Ni concentrations, indicates the ability of using the electrical signature to predict the meteorite type and its Ni content.

Using the helium injection techniques indicates negligible porosity of the studied meteorites, mostly arised from the presence of some vugs, as well as micro cracks which might have originated after the terrestrial shock.

Additional similar studies on other types of meteorites are still recommended to enrich the conclusions obtained from the present studies.

\section{References}

Binns, R.A. (1967), Cognate xenoliths in chondritic meteorites: examples in MezoMadras and Ghubara, Geochim. Cosmochim. Ac. 32, 3, 299-317, DOI: 10.1016/0016-7037(68)90017-3.

Bischoff, A., and T. Geiger (1995), Meteorites from the Sahara: Find locations, shock classification, degree of weathering, and pairing, Meteoritics 30, 1, 113-122, DOI: 10.1111/j.1945-5100.1995.tb01219.x.

Bland, P.A., F.J. Berry, T.B. Smith, S.J. Skinener, and C.T. Pillinger (1996), The flux of meteorites to the Earth and weathering in hot desert ordinary chondrite finds, Geochim. Cosmochim. Ac. 60, 11, 2053-2059, DOI: 10.1016/ 0016-7037(96)00125-1.

Bland, P.A., F.J. Berry, A.J.T. Jull, T.B. Smith, A.W.R. Bevan, J.M. Cadogan, A.S. Sexton, L.A. Franchi, and C.T. Pillinger (2002), ${ }^{57} \mathrm{Fe}$ Mössbauer spectroscopy studies of meteorites: Implications for weathering rates, meteorites flux, and early solar system processes, Hyperfine Interact. 141, 3, 481-494, DOI: $10.1023 / \mathrm{A}: 1022440217371$.

Bland, P.A., L.E. Howard, D.J. Prior, J. Wheeler, R.M. Hough, and K.A. Dyl (2011), Earliest rock fabric formed in the solar system preserved in a chondrule rim, Nat. Geosci. 4, 244-247, DOI: 10.1038/ngeo1120.

Bogard, D.D., J.C. Huneke, D.S. Burnett, and G.J. Wasserburg (1971), Xe and Kr analyses of silicate inclusions from iron meteorites, Geochim. Cosmochim. Ac. 35, 12, 1231-1254, DOI: 10.1016/0016-7037(71)90113-X.

Britt, D.T., and G.J. Consolmagno (2003), Stony meteorite porosities and densities: A review of the data through 2001, Meteorit. Planet. Sci. 38, 8, 1161-1180, DOI: $10.1111 /$ j.1945-5100.2003.tb00305.x.

Britt, D.T., D. Yeomans, K. Housen, and G. Consolmagno (2002), Asteroid density, porosity, and structure. In: W.F. Bottke, A. Cellino, P. Paolicchi, and R.P. Binzel (eds.), Asteroids III, University of Arizona Press, Tucson, 485500. 
Buchwald, V.F. (1975), Handbook of Iron Meteorites, University of California Press, Berkeley.

Christie, J.M., D.T. Griggs, A.H. Heuer, G.L. Nord Jr., S.V. Radcliffe, J.S. Lally, and R.M. Fisher (1973), Electron petrography of Apollo 14 and 15 breccias and shock-produced analogs. In: Proc. 4th Lunar Sci. Conf., 365-382.

Consolmagno, G.J., D.T. Britt, and C.P. Stoll (1998), The porosities of ordinary chondrites: Models and interpretation, Meteorit. Planet. Sci. 33, 6, 12211229, DOI: 10.1111/j.1945-5100.1998.tb01307.x.

Corrigan, C.M., M.E. Zolensky, J. Dahl, M. Long, J. Weir, C. Sapp, and P.J. Burkett (1997), The porosity and permeability of chondritic meteorites and interplanetary dust particles, Meteorit. Planet. Sci. 32, 4, 509-515, DOI: 10.1111/j.1945-5100.1997.tb01296.x.

Coulson, I.M., M. Beech, and W. Nie (2007), Physical properties of Martian meteorites: Porosity and density measurements, Meteorit. Planet. Sci. 42, 12, 2043-2054, DOI: 10.1111/j.1945-5100.2007.tb01006.x.

Crabb, J. (1983), On the sitting of noble gases in silicate inclusions of the El Taco iron meteorite (abstract). In: Lunar and Planetary Science XIV, Lunar and Planetary Institute, Houston, 134-135.

Cuzzi, J.N., R.C. Hogan, and K. Shariff (2008), Toward planetesimals: Dense chondrule clumps in the protoplanetary nebula, Astrophys. J. 687, 2, 1432-1447, DOI: $10.1086 / 591239$.

Darling, D.J. (2003), The Universal Book of Astronomy: From the Andromeda Galaxy to the Zone of Avoidance, $584 \mathrm{pp}$.

Davison, Th.M., F.J. Ciesla, G.S. Collins, and D. Elbeshausen (2014), The effect of impact obliquity on shock heating in planetesimal collisions, Meteorit. Planet. Sci. 49, 12, 2252-2265, DOI: 10.1111/maps.12394.

DeLaeter, J.R. (1972), The Mundrabilla Meteorite Shower, Meteoritics 7, 3, 285 294.

Dodd, R.T. (1981), Meteorites: A Petrologic-chemical Synthesis, Cambridge University Press, Cambridge, 368 pp.

Fegley, B. Jr. (1983), Primordial retention of nitrogen by terrestrial planets and meteorites, Proc. Lunar Planet. Sci. Conf. 13th, J. Geophys. Res. 88, A853A868.

Flynn, G.J. (2004), Physical properties of meteorites and interplanetary dust particles: Clues to the properties of the meteors and their parent bodies, Earth Moon Planets 95, 1, 361-374, DOI: 10.1007/s11038-005-9025-y.

Flynn, G.J. (2014), Porosity as a significant factor for asteroid survival, Conference abstract Asteroids, Comets, Meteors, Helsinki.

Flynn, G.J., L.B. Moore, and W. Klöch (1999), Density and porosity of stone meteorites: Implications for the density, porosity, cratering, and collisional disruption of asteroids, Icarus 142, 1, 97-105, DOI: 10.1006/icar.1999.6210. 
Gooding, J.L. (1986a), Clay-mineraloid weathering products in Antarctic meteorites, Geochim. Cosmochim. Ac. 50, 10, 2215-2223, DOI: 10.1016/00167037(86)90076-1.

Gooding, J.L. (1986b), Weathering of stony meteorites. In: J.O. Annexstad, L.S. Shultz, and H. Wänke (eds.), Antarctica. International Workshop on Antarctic Meteorites, Lunar and Planet Inst., Houston Tex., LPI Tech Rep. 86-01, 48-54.

Grady, M.M. (2000), Catalogue of Meteorites, 5th ed., Cambridge University Press, Cambridge, 696 pp.

Hamano, Y., and K. Yomogida (1982), Magnetic anisotropy and porosity of antarctic chondrites, Mem. Nat. Inst. Polar Res. 25, 281-289.

Kieffer, S.W., and C.H. Simonds (1980), The role of volatiles and lithology in the impact cratering process, Rev. Geophys. 18, 1, 143-181, DOI: 10.1029/ RG018i001p00143.

Kohout, T., K. Havrila, J. Tóth, M. Husárik, M. Gritsevich, D. Britt, J. Borovička, P. Spurný, A. Igaz, J. Svoreň, L. Kornoš, P. Vereš, J. Koza, P. Zigo, S. Gajdoš, J. Világi, D. Čapek, Z. Krišandová, D. Tomko, J. Šilha, E. Schunová, M. Bodnárová, D. Búzová, and T. Krejčová (2014a), Density, porosity and magnetic susceptibility of the Košice meteorite shower and homogeneity of its parent meteoroid, Planet. Space Sci. 93-94, 96-100, DOI: 10.1016/ j.pss.2014.02.003.

Kohout, T., M. Gritsevich, V.I. Grokhovsky, G.A. Yakovlev, J. Haloda, P. Halodova, R.M. Michallik, A, Penttilä, and K. Muinonen (2014b), Mineralogy, reflectance spectra, and physical properties of the Chelyabinsk LL5 chondrite - Insight into shock-induced changes in asteroid regoliths, Icarus 228, 78-85, DOI: 10.1016/j.icarus.2013.09.027.

Krzesińska, A. (2011), High resolution X-ray tomography as a tool for analysis of internal textures in meteorites, Meteorites 1, 1, 3-12.

Lee, M.R., and P.A. Bland (2004), Mechanisms of weathering of meteorites recovered from hot and cold deserts and the formation of phyllosilicates, Geochim. Cosmochim. Ac. 68, 4, 893-916, DOI: 10.1016/S0016-7037(03) 00486-1.

Mathew, K.J., and F. Begemann (1995), Isotopic composition of xenon and krypton in silicate-graphite inclusions of the El Taco, Campo Del Cielo, IAB iron meteorite, Geochim. Cosmochim. Ac. 59, 22, 4729-4746, DOI: 10.1016/ 0016-7037(95)00332-0.

McKay, D.S., D.D. Bogard, R.V. Morris, R.L. Korotev, P. Johnson, and S.J. Wentworth (1986), Apollo 16 regolith breccias: Characterization and evidence for early formation in the mega-regolith, Proc. Lunar Planet. Sci. Conf. 16 ${ }^{\text {th }}$, Part 2, J. Geophys. Res. 91, B4, D277-D303, DOI: 10.1029/ JB091iB04p0D277. 
McKay, D.S., D.D. Bogard, R.V. Morris, R.L. Korotev, S.J. Wentworth, and P. Johnson (1989), Apollo 15 regolith breccias: Window to a KREEP regolith. In: Proc. Lunar Planet. Sci. Conf. 19th, 19-41.

Meteoritical Bulletin (1970), New falls and discoveries, Meteoretics 5, 2, 85-109.

Meteoritical Bulletin (2013), The Meteoretical Society, Lunar and Planetary Institute, available from: http:/www.lpi.usra.edu/meteor/metbull.php?code= 16852.

Metzler, K., U. Ott, K. Welten, M.W. Caffee, and L. Franke (2008), The L3-6 Regolith Breccia Northwest Africa 869: Petrology, noble gases, and cosmogenic radionuclides, Lunar Planet. Sci. 1391, 1120.

Müller, O. (1977), Chemical studies of the Mundrabilla iron meteorite by Neutronactivation, J. Radioanal. Nucl. Ch. 38, 1-2, 499-511, DOI: 10.1007/ BF02520224.

Pesonen, L.J., K. Kuoppamäki, J. Timonen, J. Hartikainen, M Terho, and K. Hartikainen (1997), On the porosity of L and H chondrites. In: 28th Lunar and Planetary Science Conference, Abstract 1684.

Rubin, A.E. (1997), Mineralogy of meteorite groups, Meteorit. Planet. Sci. 32, 231247, DOI: $10.1111 /$ j.1945-5100.1997.tb01262.x.

Signer, P., and H.E. Suess (1963), Rare gases in the sun, in the atmosphere, and in meteorites. In: J. Geiss and E.D. Goldberg (eds.), Earth Science and Meteorites, North-Holland, Amsterdam, 241-272.

Stelzner, T., K. Heide, A. Bischoff, D. Weber, P. Scherer, L. Schultz, M. Happel, W. Schron, U. Neupert, R. Michel, R.N. Clayton, T.K. Mayeda, G. Bonani, I. Haidas, S. Ivy-Ochs, and M. Suter (1999), An interdisciplinary study of weathering effects in ordinary chondrites from the Açfer region, Algeria, Meteorit. Planet. Sci. 34, 5, 787-794, DOI: 10.1111/j.1945-5100.1999. tb01391.x.

Strait, M.M., and G.J. Consolmagno (2004), Micro crack porosity in meteorites: Clues to early history? Eos $\mathbf{8 5}, 33 \mathrm{~A}$.

Talwani, M., G. Thompson, B. Dent, H. Kahle, and S. Buck (1973), Traverse gravimeter experiment in Apollo 17, Preliminary Science Report, Spec. Publ., NASA SP-330, 13.1-13.13.

Teiser, J., and G. Wurm (2009), High-velocity dust collisions: Forming planetesimals in a fragmentation cascade with final accretion, Mon. Not. Roy. Astron. Soc. 393, 4, 1584-1594, DOI: 10.1111/j.1365-2966.2008.14289.x.

Tikoo, S.M., J. Gattacceca, B.P. Weiss, and C.R. Suavet (2013), Thermal demagnetization of shock remanent magnetization in extraterrestrial materials. In: Lunar and Planetary Science Conf., 2354, 2 pp.

Verma, H.C., and R.P. Tripathi (2004), Anomalous Mössbauer parameters in the second generation regolith Ghubara meteorite, Meteorit. Planet. Sci. 39, 10, 1755-1759. 
Vinogradov, A.P., and G.P. Vdovykin (1963), Diamonds in stony meteorites, Geochemistry 8, 743-750.

Warren, P.H. (2001), Porosities of lunar meteorites: Strength, porosity, and petrologic screening during the meteorite delivery process, J. Geophys. Res. 106, E5, 10101-10111, DOI: 10.1029/2000JE001283.

Wasson, J.T. (1974), Meteorites, Springler Verlag, London.

Wasson, J.T., and G.W. Kallemeyn (2002), The IAB iron-meteorite complex: A group, five subgroups, numerous grouplets, closely related, mainly formed by crystal segregation in rapidly cooling melts, Geochim. Cosmochim. Ac. 66, 13, 2445-2473, DOI: 10.1016/S0016-7037(02)00848-7.

Wasson, J.T., and J.W. Richardson (2001), Fractionation trends among IVA iron meteorites: contrasts with IIIAB trends, Geochim. Cosmochim. Ac. 65, 6, 951-970, DOI: 10.1016/S0016-7037(00)00597-4.

Weinke, H.H. (1977), Chemical and mineralogical investigation of a Mundrabilla specimen, Meteoret. Soc. 12, 384-386.

Weisberg, M.K., T.J. McCoy, and A.N. Krot (2006), systematics and evaluation of meteorite classification. In: D.S. Binze, H.Y. Lauretta, and McSween, Jr. (eds.), Meteorites and the Early Solar System II, University of Arizona Press, 19-52.

Welten, K.C. (1999), Concentrations of siderophile elements in nonmagnetic fractions of Antarctic $\mathrm{H}$ and L chondrites: A quantitative approach on weathering effects, Metorit. Planet. Sci. 34, 2, 259-270.

Wieler, R., H. Busemann, and I.A. Franchi (2006), Trapping and modification processes of Noble gases and nitrogen in meteorites and their parent bodies. In: D.S. Lauretta and H.Y. McSween (eds.), Meteorites and the Early Solar System II, University of Arizona Press, 499-521.

Wilkison, S.L., and M.S. Robinson (2000), Bulk density of ordinary chondrite meteorites and implications f or asteroidal internal structure, Meteorit. Planet. Sci. 35, 6, 1203-1213.

Yeomans, D.K., P.G. Antreasian, A. Cheng, D.W. Dunham, R.W. Farquhar, R.W. Gaskell, J.D. Giorgini, C.E. Helfrich, A.S. Konopliv, J.V. McAdams, J.K. Miller, Jr. W.M. Owen, P.C. Thomas, J. Veverka, and B.G. Williams (1999), Estimating the mass of asteroid 433 Eros during the NEAR spacecraft flyby, Science 285, 5427, 560-561, DOI: 10.1126/science.285. 5427.560 .

Received 28 February 2015

Received in revised form 27 August 2015

Accepted 29 October 2015 